\title{
The gut microbiota of larvae of Rhynchophorus ferrugineus Oliver (Coleoptera: Curculionidae)
}

\author{
Marcello Tagliavia ${ }^{1,3}$, Enzo Messina², Barbara Manachini', Simone Cappello² and Paola Quatrini ${ }^{*}$
}

\begin{abstract}
Background: The red palm weevil (RPW) Rhynchophorus ferrugineus Olivier (Coleoptera: Curculionidae) is one of the major pests of palms. The larvae bore into the palm trunk and feed on the palm tender tissues and sap, leading the host tree to death. The gut microbiota of insects plays a remarkable role in the host life and understanding the relationship dynamics between insects and their microbiota may improve the biological control of insect pests. The purpose of this study was to analyse the diversity of the gut microbiota of field-caught RPW larvae sampled in Sicily (Italy).

Results: The $16 \mathrm{~S}$ rRNA gene-based Temporal Thermal Gradient Gel Electrophoresis (TTGE) of the gut microbiota of RPW field-trapped larvae revealed low bacterial diversity and stability of the community over seasons and among pools of larvae from different host trees. Pyrosequencing of the $16 \mathrm{~S}$ rRNA gene V3 region confirmed low complexity and assigned 98\% of the 75,564 reads to only three phyla: Proteobacteria (64.7\%) Bacteroidetes (23.6\%) and Firmicutes (9.6\%) and three main families [Enterobacteriaceae (61.5\%), Porphyromonadaceae (22.1\%) and Streptococcaceae (8.9\%)]. More than half of the reads could be classified at the genus level and eight bacterial genera were detected in the larval RPW gut at an abundance $\geq 1 \%$ : Dysgonomonas (21.8\%), Lactococcus (8.9\%), Salmonella (6.8\%), Enterobacter (3.8\%), Budvicia (2.8\%), Entomoplasma (1.4\%), Bacteroides (1.3\%) and Comamonas (1\%). High abundance of Enterobacteriaceae was also detected by culturing under aerobic conditions. Unexpectedly, acetic acid bacteria (AAB), that are known to establish symbiotic associations with insects relying on sugar-based diets, were not detected.
\end{abstract}

Conclusions: The RPW gut microbiota is composed mainly of facultative and obligate anaerobic bacteria with a fermentative metabolism. These bacteria are supposedly responsible for palm tissue fermentation in the tunnels where RPW larvae thrive and might have a key role in the insect nutrition, and other functions that need to be investigated.

Keywords: Enterobacteriaceae, Dysgonomonas, TTGE, Pyrosequencing

\section{Background}

The red palm weevil (RPW) Rhynchophorus ferrugineus Olivier (Coleoptera: Curculionidae) is widely considered the most damaging insect pest of palms in the world, even in all the countries where it has been accidentally introduced [1]. RPW larvae feed within the apical growing point of the palms, producing a wet fermenting frass inside the tunnels [2], creating extensive damage to palm tissues and weakening the structure of the palm trunk; the resulting damage is often only visible long after infestation, when palms are close to death [3-5] (Additional file 1).

\footnotetext{
* Correspondence: paola.quatrini@unipa.it

'Department STEBICEF, University of Palermo Viale delle Scienze Ed.16,

Palermo 90128, Italy

Full list of author information is available at the end of the article
}

Insect intestinal tracts harbour rich communities of nonpathogenic microorganisms [6,7] and a single gut can harbour $10^{5}-10^{9}$ prokaryotic cells [6] that have been affiliated to twenty-six phyla, at least for the insects studied to date [8]. It is increasingly evident that the microbiota of animals (humans included) plays a remarkable role in the host life. The genetic wealth of the microbiota affects all aspects of the holobiont's (host plus all of its associated microorganisms) fitness such as adaptation, survival, development, growth, reproduction and evolution [9]. When not strictly essential for survival, the insect gut microbiota affects many aspects of host phenotype; it can increase the digestive efficiency of soluble plant polysaccharides $[10,11]$ and can mediate interactions between the host and potential pathogens [12]. Recent work suggests that the gut microbiota not only provide nutrients, but is also involved in the development 
and maintenance of the host immune system. However, the complexity, dynamics and types of interactions between the insect hosts and their gut microbiota are far from being well understood [13]. Understanding the relationship dynamics between insects and their microbiota can improve the biocontrol of insect pests, which is a focus of much insect gut microbiology studies.

Despite the economic and environmental damages caused by the RPW in all the areas where it is endemic and where it has been accidentally introduced, little is known about its gut microbiota. The bacterial community that is embedded in the frass produced inside the tunnels of the palm Phoenix canariensis Chabaud by the RPW larvae is dominated by Enterobacteriaceae with a facultative fermentative metabolism [2].

The purpose of this study was to analyse the diversity of the gut microbiota of the $R$. ferrugineus larvae, that represent the development stage responsible for damages to palms. Field-caught larvae were sampled from its favourite host $P$. canariensis in different seasons and sites in Sicily (Italy), and analysed for the diversity of their gut microbiota. The analysis of the bacterial community was carried out by culture-independent methods using temporal thermal gradient gel electrophoresis (TTGE) and FLX454 pyrosequencing of PCR-generated amplicons from the $16 \mathrm{~S}$ rRNA gene.

\section{Results}

Total diversity of the gut microbiota of field caught $R P W$ larvae

Bacterial TTGE profiles were generated using PCRamplified bacterial 16S rRNA gene fragments from the content of pooled RPW larval guts collected from the trunks of infested $P$. canariensis palms in three different seasons and two areas in Sicily (Italy). TTGE band profiles indicate the presence of an average of 25 bands per sample, that correspond to putative bacterial phylotypes in RPW larval guts. An example of TTGE gel is shown in Figure 1, where three different pooled guts collected in December 2010 and April 2011 in Palermo (lanes 1 and 2, respectively), and in April 2011 in San Vito lo Capo (Trapani, lane 3) were analysed. All samples shared 16 bands, while 4, 2 and 4 bands were unique for samples 1, 2, 3, respectively. Similar profiles were obtained from larvae collected in October both in Palermo and Trapani (data not shown). Random sequencing of TTGE bands identified the presence of uncultured Gammaproteobacteria (of the genera Pantoea and Enterobacter) and Firmicutes (of genera Megasphaera and Clostridium) (Figure 1).

\section{Pyrosequencing}

Pyrosequencing of the $16 \mathrm{~S}$ rRNA gene amplicons was carried out on three pooled RPW larval guts sampled in Palermo in April 2011 (indicated as lot A). The analysis produced a total of 79,204 reads with an average length of 320.6 nucleotides that became, after quality filtering and clustering (needed for Ribosomal Database Project analysis), 75,564 for 97\%, 76,724 for 95\%, and 73,579 for $90 \%$ of similarity (Additional file 2). Reads were assigned to 41 operational taxonomic units (OTUs) at $90 \%$ of sequence identity threshold, and to 45 OTUs at $95 \%$ and 97\% identity threshold, respectively, in order to perform rarefaction analysis. The total number of clusters obtained after filtering was of 2,107 (1,756 singletons) for 97\%, 910 (530 singletons) for 95\%, and 244 (124 singletons) for $90 \%$ of similarity, respectively. The rarefaction curves tended towards saturation at similar numbers of clusters at 97\%, 95\% and 90\% pairwise ID thresholds (Figure 2). Subsequent analysis was, therefore, conducted at $97 \%$ ID.

Only three phyla account for $98 \%$ of the reads: these are Proteobacteria (64.7\%), Bacteroidetes (23.6\%) and Firmicutes $(9.6 \%)$; the remaining $2 \%$ is represented by Tenericutes $(1.4 \%)$ Fusobacteria $(0.4 \%)$ and other Bacteria $(0.2 \%)$ (Figure 3a). Proteobacteria are mainly represented by Gammaproteobacteria (96.7\%) followed by Betaproteobacteria (2.71\%) (Figure 3b). More than $98 \%$ of the reads were classified at the family level, with Enterobacteriaceae representing the $61.5 \%$ of the assemblage, followed by Porphyromonadaceae $(22.1 \%)$ and Streptococcaceae (8.9\%) (Additional file 3). More than half of the reads (52.7\%) could be classified at the genus level and eight bacterial genera were detected in the larval RPW gut at an abundance $\geq 1 \%$ (Figure 4a). Dysgonomonas sequences account for the $21.8 \%$ of the whole sequences and this is the most represented genus in the gut of RPW larvae, followed by Lactococcus (8.9\%) Salmonella (6.8\%), Enterobacter (3.8\%), Budvicia (2.8\%), Entomoplasma (1.4\%) Bacteroides (1.3\%) and Comamonas (1\%). Other twelve genera are represented at a value between $1 \%$ and $0.1 \%$ (Figure $4 \mathrm{~b}$ ). The phylogenetic tree of $16 \mathrm{~S}$ rRNA gene amplicons clustered at $97 \%$ consensus is shown in the Additional file 4.

\section{Diversity of cultivable bacteria}

Bacterial isolation under aerobic conditions was carried out on three lots of three pooled RPW larval guts (lots A, B, C), all sampled in April 2011. The dilution plate counts on NA gave an average of $1.5 \times 10^{7} \mathrm{CFU}_{\text {gut }^{-1}}$, without differences among the three pools. Forty-four phenotypically different isolates, obtained from the dilution plates of the three pooled guts independently, were grouped into ten OTUs (Table 1) by ARDRA analysis with the restriction enzymes $A f a I$ and AluI, that gave five and seven different restriction profiles, respectively (data not shown). 16S rRNA gene sequencing of representative isolates assigned the cultivable bacteria to the families Enterobacteriaceae (68.2\%), Bacillaceae (20.5\%), Comamonadaceae (9\%) and Xanthomonadaceae (2.7\%) 


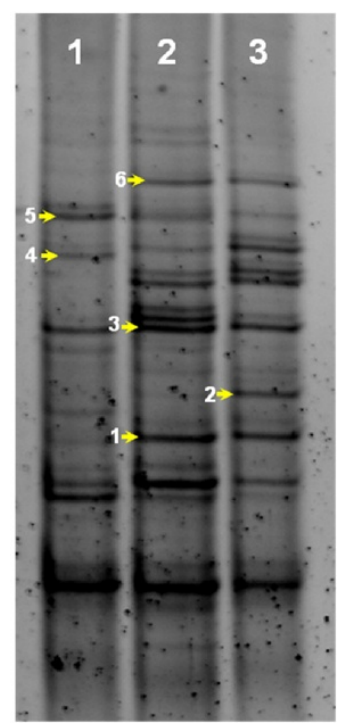

\begin{tabular}{ccllcc}
\hline $\begin{array}{c}\text { TGGE } \\
\text { band } \\
\text { number }\end{array}$ & nt & \multicolumn{1}{c}{$\begin{array}{c}\text { Closest sequence match (accession } \\
\text { number) }\end{array}$} & Division/subdivision & $\begin{array}{c}\text { Score } \\
\text { \% sequence } \\
\text { similarity) }\end{array}$ & $\begin{array}{c}\text { E } \\
\text { value }\end{array}$ \\
\hline 1 & 143 & $\begin{array}{l}\text { Pantoea sp. enrichment culture clone } \\
\text { YFZ27 16S (GQ273907) }\end{array}$ & Gammaproteobacteria & $259(98)$ & $4 \mathrm{e}-66$ \\
2 & 137 & $\begin{array}{l}\text { Uncultured bacterium (Enterobacter } \\
\text { sp.) clone P4-12 (AY119386) }\end{array}$ & Gammaproteobacteria & $239(98)$ & $4 \mathrm{e}-60$ \\
3 & 157 & $\begin{array}{l}\text { Uncultured Enterobacter sp. clone } \\
\text { F4apr.28 (GQ418069) }\end{array}$ & Gammaproteobacteria & $268(97)$ & $7 \mathrm{e}-69$ \\
4 & 169 & $\begin{array}{l}\text { Uncultured soil bacterium (Clostridium } \\
\text { sp.) clone CRS5546T-1 (GU365991.1) }\end{array}$ & Firmicutes & $294(98)$ & $1 \mathrm{e}-76$ \\
5 & 153 & $\begin{array}{l}\text { Uncultured Megasphaera sp. clone } \\
\text { MANPL08H07 (GU480445.1) }\end{array}$ & Firmicutes & $180(88)$ & $4 \mathrm{e}-42$ \\
6 & 117 & $\begin{array}{l}\text { Uncultured Megasphaera sp. clone } \\
\text { MANPL08H07 (GU480445.1) }\end{array}$ & Firmicutes & $206(98)$ & $7 \mathrm{e}-50$ \\
\hline
\end{tabular}

Figure 1 Temporal Thermal Gradient gel Electrophoresis (TTGE) profiles of PCR-amplified 16S gene fragments derived from field collected larvae of Rhynchophorus ferrugineus. Lane 1: TTGE profile of a pool of three larvae (average weight: $3.25 \mathrm{~g}$; SD: 0.55) collected in December 2010 in a palm tree in the urban area of Palermo (Italy). Lane 2: TTGE profile of a pool of three larvae collected in April 2011 (average weight: 3.86 g; SD: 0.64) in the urban area of Palermo (Italy). Lane 3: TTGE profile of a pool of three larvae collected in April 2011 (average weight 3.60 g; SD: 0.53) in San Vito lo Capo (Trapani, Italy).

(Table 1). The genus Citrobacter is the most abundant among the isolates (29.55\%), followed by the genera Klebsiella (20.45\%), Bacillus (20.45\%) and Budvicia (11.36\%).

Most of the sequences having homology with those of RPW isolates are from bacteria isolated from animals' gut or from plants (endophytes), as well as from wastewater or bioremediation treatment plants and anaerobic marine sediments. Some of the Citrobacter and Klebsiella $16 \mathrm{~S}$ rRNA sequences are almost identical to those from bacteria previously isolated from the frass produced by RPW larvae in the tunnels of palm trees (Additional file 5) [2].

Several attempts were made to surface-sterilize the larvae using different protocols; nevertheless the control plates, obtained by streaking on Nutrient Agar the cuticle of sterilized larvae, showed the growth of some colonies. Seven of these colonies were purified and analysed by ARDRA as described above. One representative isolate for each of the three OTUs obtained was chosen for 16S rRNA gene sequencing and all the three isolates were affiliated to the genus Bacillus, with their closest relatives in B. thuringiensis [14] and B. aerophilus [15] (Additional file 5).

Enrichment cultures were set for the isolation of acetic acid bacteria (AAB). $\mathrm{AAB}$ are known to establish symbiotic associations with the midgut of insects relying on sugarbased diets, such as nectars, fruit sugars, or phloem sap [16]. At the end of the incubation period, four $\mathrm{CaCO}_{3}$ dissolving colonies were isolated from the enrichment cultures and identified by $16 \mathrm{~S}$ rDNA sequencing. Unexpectedly, all the isolates that were able to use sorbitol and to dissolve $\mathrm{CaCO}_{3}$ in the agar plates were assigned to the genus Klebsiella (Additional file 5). 


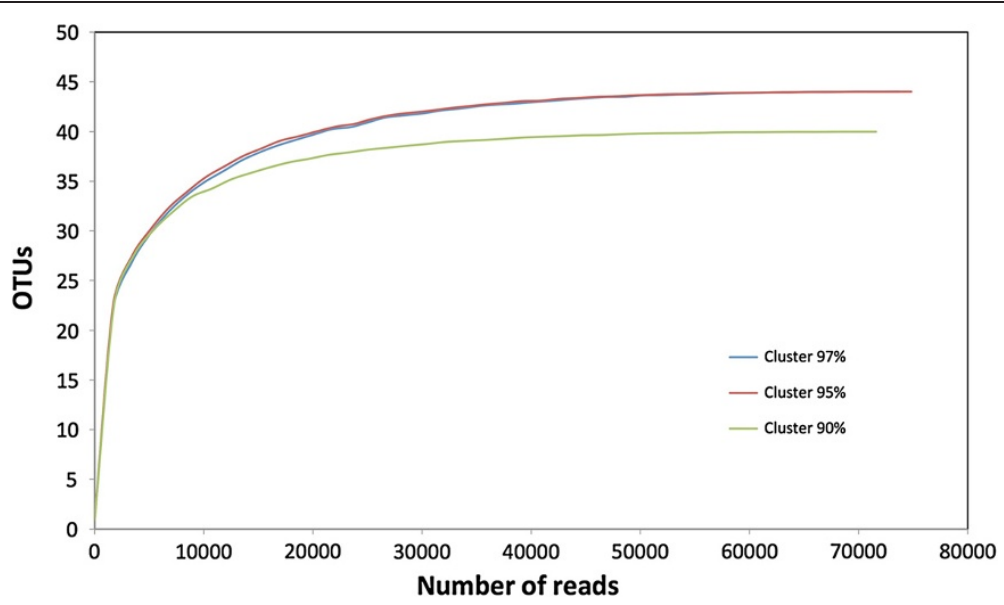

Figure 2 Rarefaction curves of OTUs clustered at different \% ID in the gut of RPW larvae.

\section{Discussion}

In this study, the diversity of the gut microbiota of Rhynchophorus ferrugineus (RPW), collected on infested palm trees Phoenix canariensis, was first analysed by TTGE of the PCR-amplified bacterial 16S rRNA gene fragments. The TTGE profiles obtained from different lots of larvae, sampled in different seasons and geographical sites, show relatively low complexity (average of 25 OTUs) and high similarities regardless the site of sampling and season, suggesting that the composition of the RPW microbiota is stable over time and among pools of larvae from different host trees.

In order to identify the gut bacterial community of RPW larvae, the variable region 2 (V2) of the bacterial $16 \mathrm{~S}$ rRNA gene, already successfully employed in the analysis of several microbial communities [17-19], was analysed by pyrosequencing. The analysis confirmed that the bacterial community of the RPW larvae has low diversity although, as expected, more OTUs were identified in respect to TTGE analysis. Contrasting results are reported for bacterial diversity of gut microbiota of other coleopterans; high diversity and complexity was observed among tree xylophagous beetles that rely on the microbiota for efficient lignocellulose metabolism and thus survival [8], while low diversity was recorded in the gut of the red turpentine beetle [20]. The RPW larvae are the major responsible for the palm damages because they live throughout their development inside the palm stem, feeding exclusively on palm tissues. This peculiar lifestyle may account for the low diversity detected in the gut of field sampled larvae of $R$. ferrugineus, regardless the investigation methods. There is strong evidence

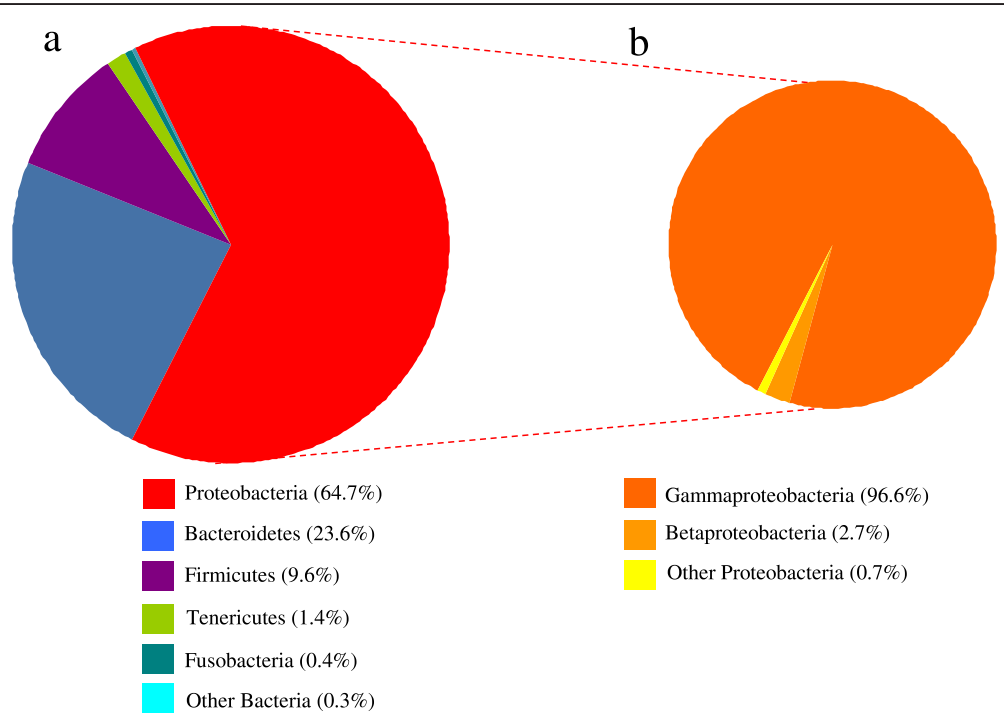

Figure 3 Relative abundance of a) bacterial Phyla and b) classes of Proteobacteria in the gut of field caught RPW larvae as detected by pyrosequencing. Values $\leq 0.1 \%$ are included in "other bacteria" (see Additional file 2). 

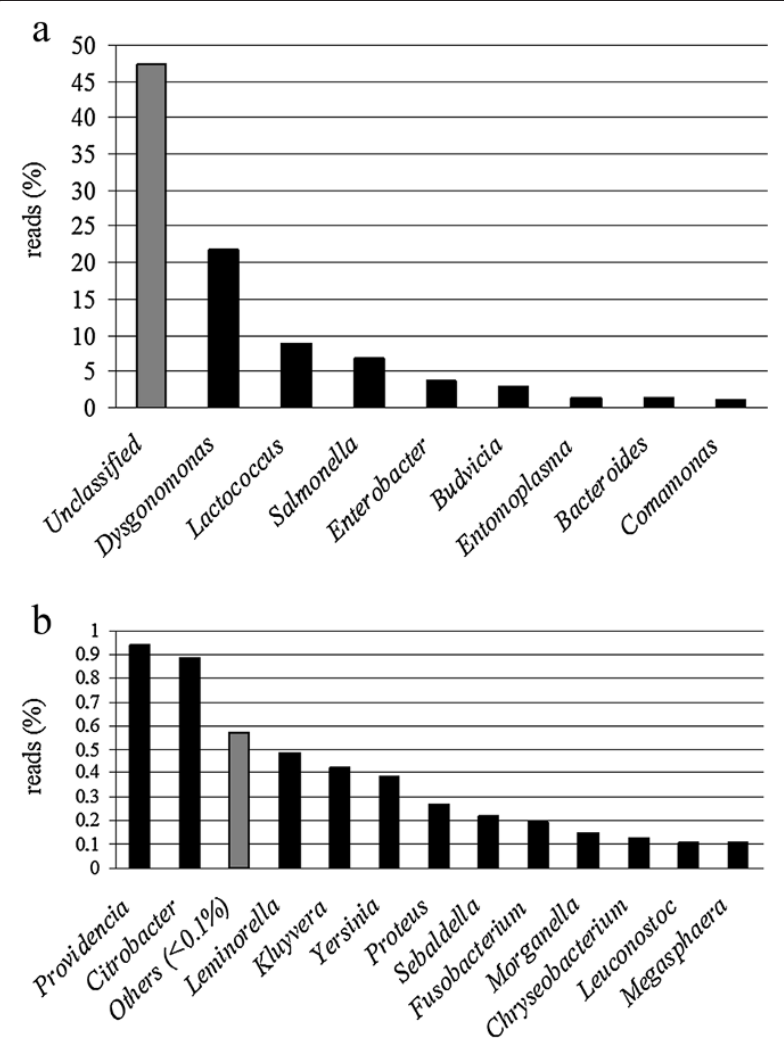

Figure 4 Relative abundance of bacterial genera a) above 1\% and b) below $1 \%$ in the gut of field caught RPW larvae as detected by pyrosequencing. "Others" indicates 35 genera below $0.1 \%$ (see Additional file 2).

that mainly taxonomy and diet of the host can affect an organism's gut microbial community [8,21]. RPW larvae feed on nutrient-poor palm tissues and sap that contain mainly sucrose and glucose [22] but are poor of nitrogen $[20,23,24]$; an excess of sugars is known to reduce the complexity of the gut microbiota [25,26]. Conversely, complex substrates, such as lignocellulose-derived materials, select complex gut bacterial communities even in highly divergent insect groups [8]. Feeding on live trees may also expose the insect to tree physiological responses, that may play a selection pressure on its microbiota. Moreover, the antimicrobial activity of larvae [27] may further shape the gut community of RPW.

The gut of RPW larvae is dominated by three phyla, Proteobacteria, Bacteroidetes and Firmicutes, that account for $98 \%$ of the assemblage. These same phyla were also found in the sugarcane weevil Sphenophorus levis Vaurie [28], which belong to the Dryophthorinae subfamily as $R$. ferrugineus, and that is the only weevil, to our best knowledge, that has been characterized in its microbiota. Proteobacteria and Firmicutes represent also the predominant bacterial phyla in bark beetles [20] and, in general, in all insect guts studied so far, while Bacteroidetes are more prevalent in termites, detritivorous insects and, among Coleoptera, in the root feeding Melolontha melolontha L. (Coleoptera: Melolonthidae) [8].

The genus Dysgonomonas is, unexpectedly, the most represented in the gut of RPW larvae. Dysgonomonas (phylum Bacteroidetes) are facultative anaerobes with a fermentative metabolism producing acids and no gas, that were first recovered from a human infected gall bladder [29]. Dysgonomonas is described as an opportunistic human pathogen but its habitat is unknown. Members of this genus were recently detected in microbial fuel cells (MFC) anode biofilms [30], in the gut of house flies (Musca domestica L.) [31] and in eight separate Drosophila populations where its presence is not restricted to any one locality, species, or diet type [21]. Its presence in such a high number in the insect gut, and in RPW gut in particular, deserves to be further investigated because it might play an important role in the insect biology.

Salmonella, Enterobacter, Budvicia and other Enterobacteriaceae are highly represented in the 454 assemblage; as in other insects, they could play a beneficial role in nutrition, in the degradation of plant polymers and fermentation of sap sugars. Members of Enterobacteriaceae were also identified as intracellular symbionts of grain weevils Sitophilus spp. (Curculionidae) [32] and some isolates are able to fix nitrogen, thus contributing to a supplementary nitrogen source $[20,23]$.

Entomoplasma is the sixth genus to be represented in terms of abundance in the RPW gut (3\%). Entomoplasma is a glucose fermenting non-helical mollicutes and its presence in the RPW gut is consistent with what is presently known of its habitat. This genus could be considered a marker of the Coleopteran microbiota. All five currently described Entomoplasma species, in fact, were isolated from the gut or haemolymph of various firefly beetles (Coleoptera: Lampyridae) and green tiger beetles (Coleoptera: Cicindelidae) [33].

In spite of being affiliated to three different phyla, all the first six dominating bacterial genera of the RPW gut are facultative or obligate anaerobes with a fermentative metabolism. Dysgonomonas is a facultative anaerobe that produces acids and no gas; Lactococcus is a omofermenting lactic acid bacterium and some species can produce acetoin. The other three dominating genera belong to the Enterobacteriaceae characterized by mixed acid fermentation with production of lactic, acetic, succinic acid and ethanol (Salmonella), or 2,3-butanediol fermentation, producing butanediol, ethanol, $\mathrm{CO}_{2}$ and $\mathrm{H}_{2}$ (Enterobacter and Budvicia). Entomoplasma is also a glucose fermenting bacterium. These results suggest that the peculiar life-style of RPW larva and its gut exert a strong selective pressure towards those microbial species that are specialised to grow in a high sugar environment and that these species probably have a competitive advantage on those that cannot tolerate organic acids. 
Table 1 Phylogenetic affiliation of representative bacterial isolates from the gut of $R$. ferrugineus larvae as assigned by the Naïve Bayesian rRNA Classifier Version 2.4, of the Ribosomal Database Project II (RDP) and EMBL/SwissProt/ GenBank non-redundant nucleotide database BLAST analysis

\begin{tabular}{|c|c|c|c|c|c|c|c|c|}
\hline OTU & Phylum & Class & Family & $\begin{array}{l}\text { N. of isolates } \\
\text { in the OTU }\end{array}$ & Isolate & $\begin{array}{l}\text { Most closely related } \\
\text { sequence (MegaBLAST) }\end{array}$ & $\begin{array}{l}\text { Genbank } \\
\text { acc. N. }\end{array}$ & $\begin{array}{l}\text { ID } \\
\%\end{array}$ \\
\hline A & Proteobacteria & Betaproteobacteria & Comamonadaceae & 4 & RPWA5.3 & $\begin{array}{l}\text { Comamonas nitrativorans strain } \\
23310\end{array}$ & NR025376.1 & 98 \\
\hline \multirow[t]{2}{*}{ B } & & Gammaproteobacteria & Enterobacteriaceae & 5 & RPWA3.3 & Budvicia aquatica strain Eb 13/82 & NR025332.1 & 98 \\
\hline & & & & & RPWC1.3 & Uncultured bacterium clone $\mathrm{J44}$ & GQ451198.1 & 99 \\
\hline C & & & & 10 & RPWA2.8 & Citrobacter koseri strain LMG 5519 & HQ992945.1 & 99 \\
\hline D & & & & 3 & RPWC2.4 & $\begin{array}{l}\text { Citrobacter koseri complete genome } \\
\text { ATCC BAA-895 }\end{array}$ & CP000822.1 & 99 \\
\hline$E$ & & & & 1 & RPWC1.2 & $\begin{array}{l}\text { Uncultured bacterium clone } \\
\text { MFC4P_173 }\end{array}$ & JF309179.1 & 99 \\
\hline \multirow[t]{4}{*}{$F$} & & & & 9 & RPWB1.1 & Klebsiella oxytoca strain LF-1 & EF127829.1 & 99 \\
\hline & & & & & RPWA1.1 & Klebsiella oxytoca strain NFL28 & GQ496663.1 & 99 \\
\hline & & & & & RPWA1.5 & Klebsiella sp. 2392 & JX174269.1 & 93 \\
\hline & & & & & RPWC4.3 & Klebsiella sp. Co9935 & DQ068764.1 & 99 \\
\hline G & & & & 1 & RPWC2.2 & Proteus sp. LS9(2011) & JN566137.1 & 99 \\
\hline $\mathrm{H}$ & & & & 1 & RPWA1.6 & $\begin{array}{l}\text { Salmonella enterica subsp. arizonae } \\
\text { serovar } 62: z 4, z 23\end{array}$ & СР000880.1 & 99 \\
\hline I & & & Xanthomonadaceae & 1 & RPWC3.1 & Stenotrophomonas sp. DD7 & JQ435720 & 99 \\
\hline \multirow[t]{4}{*}{$J$} & Firmicutes & Bacilli & Bacillaceae & 9 & RPWA4.1 & Bacillus muralis strain cp5 & JN082264.1 & 99 \\
\hline & & & & & RPWB1.3 & Bacillus sp. 4014 & $J X 566611$ & 99 \\
\hline & & & & & RPWB1.4 & Bacillus sp. DP5(2011) & JF825992.1 & 99 \\
\hline & & & & & RPWB3.2 & $\begin{array}{l}\text { Bacillus megaterium strain NBRC } \\
12068\end{array}$ & AB680229.1 & 99 \\
\hline
\end{tabular}

Interestingly, two genera of Enterobacteriaceae, Pantoea and Rahnella, which had previously been isolated from frass, were not detected in the gut. Rahnella isolates from frass have their closest relatives in components of the microbiota of the red turpentine beetle Dendroctonus valens LeConte (Coleoptera: Scolytidae) [20] and of the larvae of the lepidopteran Hepialus gonggaensis Fu \& Huang (Lepidoptera: Hepialidae) [34]; Pantoea from frass are close to bacteria of the fungus garden of the leaf-cutter ant Atta colombica GuérinMéneville (Hymenoptera: Formicidae), where they contribute to external plant biomass degradation and nitrogen fixation [35] (Additional file 5). High identities of RPW gut isolates with frass isolates and with other beneficial insect-associated bacteria suggest that the RPW gut microbiota cooperates, in a continuum with the frass microbiota, to the fitness of the larva inside the palm. Thus, while a unique midgut-associated microbiota can be distinguished from the environmental bacterial community in some insects [36], the peculiar lifestyle of RPW larvae makes such discrimination difficult or probably meaningless. In fact, RPW larvae feed in a very confined environment, consisting of tunnels burrowed in the palm trunk, where they continuously ingest both fresh palm tissues and frass, composed of chewed and/ or digested plant tissue, so that re-acquisition by ingestion of bacteria from the environment is highly probable to occur.

Beyond nutritional aspects, the gut and frass fermentation products, such as acetoin and organic acid derivatives, ethyl esters, act as insect aggregation pheromones playing a role of attraction to other insects and promoting new oviposition events on the same tree [37].

Acidification caused by bacterial fermentation could also confer other advantages to the insect host, as some microbial toxins of Lepidoptera, such as Bacillus thuringiensis toxins, are activated by alkaline conditions. Thus, the RPW microbiota might help protect this insect from B. thuringiensis toxin by decreasing the midgut $\mathrm{pH}$ [38]. Moreover, together with that of fermenting yeasts, the bacterial metabolic activity increases the temperature inside the palm tissues, helping weevil overwintering [39].

It is well known that culture-based methods fail in describing the total diversity of natural bacterial communities so that, as expected, culture-independent techniques yielded a higher diversity of bacteria. Culturing under aerobic conditions led to the detection of nine bacterial genera in the RPW larval gut. Both pyrosequencing and 
culturing revealed that Enterobacteriaceae is the most represented bacterial family in the gut of RPW larvae.

In this work, the culture-based approach helped in obtaining a better description of some members of Enterobacteriaceae as the complete sequence of the $16 \mathrm{~S}$ rRNA gene could be obtained from the isolated bacteria. The pyrosequencing approach, that relies upon a short 16S rRNA gene fragment, did not detect sequences of the genus Klebsiella, that was instead abundantly isolated by culturing. Failing of its detection could be due to low variability of the V2 region between Klebsiella and Enterobacter [12,40] and the sequences of Klebsiella might have been included in the genus Enterobacter by the RDP Classifier software.

Another genus detected by cultivation but absent in the 454 assemblage was Bacillus that might be present at very low levels in the RPW gut, so that its detection might be impaired by PCR biases. Bacilli isolated from the gut are close to $B$. muralis and $B$. simplex, and cluster separately from palm endophyte bacilli and frass bacilli previously isolated, that are related to the B. cereus/thuringiensis group.

Cuticle Bacillus isolates, that survived sterilization procedures, form a separate cluster from gut bacilli and are closer to the Bacillus isolates previously obtained from frass and from healthy palms as endophytes [2] (Additional file 5). This suggest that they belong to a bacterial community external to the larvae, that might contribute to the fitness of larvae inside the plant tissues. The cuticle aerobic spore-forming bacteria might produce antimicrobial molecules that could negatively affect the sensitivity of the larvae to entomopathogenic fungi and bacteria [41].

A low bacterial diversity and the presence of a prevailing sugar-fermenting microbiota suggest that the digestion of plant polymers (cellulose, hemicellulose) is not a primary function of the RPW larvae. However, cellulolytic and hemicellulolytic bacteria were previously isolated by enrichment cultures from the gut of RPW larvae and were mainly affiliated to the Gamma and Alphaproteobacteria of the genera Pseudomonas, Enterobacter Microbacterium and Paenibacillus [2]. The presence of these genera in the RPW gut was confirmed by pyrosequencing (Additional file 6). Matching the 454-reads with the 16S rRNA gene sequences of the gut cellulolytic isolates, we obtained up to $99 \%$ identity of cluster_3902 (3 sequences) with the cellulolytic isolate Pseudomonas sp. R-8 (Genbank accession JN167546) and $98 \%$ identity of five different clusters (for a total of 159 sequences) with the cellulolytic RPW gut isolate Enterobacter sp. R-10 (Genbank accession JN167548) (Additional file 6). Both isolates were positive to the Congo Red test and able to grow on xylan in pure culture [2] but their hydrolytic activity on plant polymers in situ has to be demonstrated (as, for example, it might be inhibited by sap sugars).
The gut of insects that rely on sugar-based diets, particularly those belonging to the orders Diptera, Hymenoptera and Hemiptera, are often dominated by acetic acid bacteria (AAB), [16]. Although the larval RPW diet is almost exclusively based on sugars, we were unable to detect $\mathrm{AAB}$ using a consolidated method based on the enrichment culture technique [42]. Moreover, the absence of AAB in the RPW gut was confirmed by deep sequencing, where only two sequences were affiliated to the genus Acidisoma (Acetobacteriaceae) (Additional file 2). AAB are common in sugary acidic and alcoholic habitats, but are usually limited by nutrients other that their primary carbon source. AAB are common in fruit-feeding Drosophila species but are absent in flower-feeding flies [21]. Their absence in the RPW larvae could be explained by microbial interactions occurring inside the gut. The enrichment cultures set to specifically isolate $\mathrm{AAB}$ led, instead, to the isolation of Klebsiella strains that could outcompete AABs and that could fulfil also the nitrogen fixation function $[20,43]$, allowing the insect to live on a substrate with a high $\mathrm{C} / \mathrm{N}$ ratio.

\section{Conclusions}

The RPW microbiota is composed mainly of facultative and obligate anaerobic bacteria with a fermentative metabolism. These bacteria might have a key role in the insect nutrition, and other functions that need to be investigated. Further research, focusing on the functional traits of the bacteria inhabiting the gut of $R$. ferrugineus, is critically important to establish if some bacteria may exert an essential role for the insect or might represent an obstacle for the optimization and promotion of the use of entomopathogenic fungi and bacilli in an integrated pest management approach.

\section{Methods}

\section{Sampling of RPW larvae and gut extraction}

Field caught RPW late instar larvae (hereafter called larvae) were collected in Winter and Spring from infested palms of the species Phoenix canariensis Chabaud, located in the urban and peri-urban area of Palermo, and in San Vito Lo Capo (Trapani), (Italy) (Additional file 1). The palms were cut down following phytosanitary measures for the control and eradication of $R$. ferrugineus (Regional Decree 6 March 2007). The palms were not treated by chemical or biological pesticides.

The temperature was measured in 6 healthy and 6 infested palm trees during sampling at April 2011. Temperature was measured using a Bi-metal control digital thermometer (Wika - 360A005A4HS) by burrowing a small hole in the trunks, where the probe was inserted inside the palm trees. The average temperature of infested palm trees was $32.13^{\circ} \mathrm{C} \pm 0.83$, while the average temperature calculated at the same time for healthy palm trees was $25.95^{\circ} \mathrm{C} \pm$ 0.71 and the ambient atmosphere was $26.2^{\circ} \mathrm{C}$. 
All sampled larvae were maintained in a plastic box with their own frass, taken from tunnels, and immediately transported to the laboratory for analysis. Each specimen was weighed, placed at $-80^{\circ} \mathrm{C}$ for $30 \mathrm{~min}$ and surface sterilized with sodium hypochlorite and ethanol as described elsewhere [2,44]. Late-instar larvae (average weight $=3.5 \mathrm{~g} \pm 0.7 \mathrm{~g}$, body length $3 \mathrm{~cm} \pm 0.6$ headcapsule $6.0 \mathrm{~mm} \pm 0.8$ ), corresponding in general to the 7 th instar, were used. Larvae sterilization control was performed by streaking each intact larva on the surface of a Nutrient Agar (NA, Difco) plate. Larvae were dissected, the whole gut was aseptically removed and used for DNA extraction and bacterial isolation. Each sample consisted of the content of three pooled guts extracted from three larvae of the same weight and caught at the same time in the same palm tree.

\section{TTGE analysis}

Total bacterial diversity was assessed by Temporal Thermal Gradient gel Electrophoresis (TTGE) of 16S rDNA PCR products. DNA extraction form guts was carried out using the QIAamp DNA Stool Mini Kit, QIAGEN (Qiagen, Hilden, Germany) according to the manufacture's protocol and performing a lysis step at $95^{\circ} \mathrm{C}$ in order to obtain better lysis of Gram positive bacteria. A DNA region of approximately 200 base pairs was PCR-amplified from total DNAs. PCR was carried out using universal eubacterial oligonucleotide primers 341f-GC (5'-CGCCC GCCGCGCGCGGCGGGCGGGGCGGGGGCACGGG GGGCCTACGGGAGGCAGCAG-3') and 534r (5'-A TTACCGCGGCTGCTGG-3') targeting the variable V3 region of the $16 \mathrm{~S}$ rRNA gene [45].

PCR were carried out using Phire Hot Start II DNA Polymerase (Thermo Scientific), 1X PCR buffer, $500 \mathrm{nM}$ each primer, $0.20 \mathrm{mM}$ dNTP and. $100 \mathrm{ng}$ of DNA in a final volume of $25 \mu$ l. Cycling conditions were: $98^{\circ} \mathrm{C}$ for $30 \mathrm{sec}$, followed by $35 \mathrm{cycles}$ of $98^{\circ} \mathrm{C}$ for $10 \mathrm{sec}, 58^{\circ} \mathrm{C}$ for $10 \mathrm{sec}$ and $72^{\circ} \mathrm{C}$ for $15 \mathrm{sec}$, followed by a final extension at $72^{\circ} \mathrm{C}$ for $2 \mathrm{~min}$.

PCR products were fractionated on polyacrylamide gel (polyacrylamide:bis 29:1) $8 \%$, Urea $7 \mathrm{M}$, Formamide $10 \% \mathrm{v} / \mathrm{v}$, TAE 1.5X, at $70 \mathrm{~V}$ for $21 \mathrm{~h}$ in DCode (Bio-Rad) apparatus with a starting temperature of $57^{\circ} \mathrm{C}$ and a temperature ramp rate of $0.4^{\circ} \mathrm{C} \mathrm{h}^{-1}$. Gels were stained with SYBRGold nucleic acid gel stain (Molecular Probes, Invitrogen) for $30 \mathrm{~min}$ and viewed under UV light.

Random bands were excised with a sterile scalpel immediately after visualisation, rinsed in $100 \mu \mathrm{l}$ of distilled water and incubated in 30-50 $\mu \mathrm{l}$ of water, depending on band intensity, to elute DNA. DNA was re-amplified using the PCR-DGGE primers and products checked by agarose gel electrophoresis. The PCR products were purified using the QIAGEN PCR purification kit (Qiagen Hilden, Germany) and sequenced using the 534r primer. Partial bacterial $16 \mathrm{~S}$
rRNA gene sequences (approximately $160 \mathrm{bp)} \mathrm{were} \mathrm{sub-}$ jected to a NCBI nucleotide BLAST search (http://blast. ncbi.nlm.nih.gov/Blast.cgi) to identify sequences of the highest similarity. TTGE band sequences longer than 150 bp were deposited in Genbank under accession number KC763481 to KC763483.

\section{Pyrosequencing}

The variable region 2 (V2) of the bacterial $16 \mathrm{~S}$ rRNA gene was amplified with the primers $27 \mathrm{~F}$ (5'-AGAGTTT GATCMTGGCTCAG-3') and 338R (5'-TGCTGCCTCC CGTAGGAGT-3') [46], modified with Adaptor A (CGTAT CGCCTCCCTCGCGCCATCAG) and Adaptor B (CTATG CGCCTTGCCAGCCCGCTCAG), separated by the four nucleotides in italics, respectively, for pyrosequencing (Roche). The analysis was performed on DNAs extracted from a set of three larvae sampled in April 2011 (lot A) in the urban area of Palermo, Italy. PCRs for the biological samples and reagent control were carried out in five replicates with $0.6 \mathrm{U}^{\text {Platinum }}{ }^{\circ}$ Taq DNAPolymerase high fidelity (Invitrogen) in 1X PCR buffer, $2 \mathrm{mM}$ $\mathrm{MgCl}_{2}, 300 \mathrm{nM}$ each primer, $0.24 \mathrm{mM} \mathrm{dNTP}$ and $100 \mathrm{ng}$ of DNA in a final volume of $25 \mu \mathrm{l}$. Cycling conditions were: $94^{\circ} \mathrm{C}$ for $5 \mathrm{~min}$, followed by 35 cycles of $94^{\circ} \mathrm{C}$ for $20 \mathrm{sec}$, $56^{\circ} \mathrm{C}$ for $30 \mathrm{sec}$ and $68^{\circ} \mathrm{C}$ for $40 \mathrm{sec}$, followed by a final extension at $68^{\circ} \mathrm{C}$ for $5 \mathrm{~min}$.

Equal volumes of the five reaction products were pooled and purified using the QiAquick Gel Extraction Kit $\left(\right.$ QIAGEN $\left.^{\circ}\right)$. A further purification step was carried out using the Agencourt Ampure XP (Beckman Coulter Genomics), in order to obtain the required pyrosequencing-grade purity, that was assessed by loading a sample in a High Sensitivity DNA chip Agilent 2100 Bioanalyser.

PCR products were mixed for emulsion PCR at one copy per bead using only 'A' beads for unidirectional sequencing. Beads were subjected to sequencing on the Roche 454 GS FLX Titanium platform (Roche, Switzerland). Sequences obtained were directly clustered (no trimming was required) with CD-HIT 454 software [47] using three different similarity threshold: 90\%, 95\%, and 97\%. This software was also used to extract representative cluster consensus sequences. After they were filtered and annotated using the Ribosomal Database Project (RDP) classifier software [48]. Filtering consisted of deleting sequences shorter than $100 \mathrm{bp}$ or containing a number of unknown nucleotides $(\mathrm{N})$ greater than five. Finally, all sequences (clustered plus singletons) were annotated with RDP classifier using default parameters and then parsed to obtain a readable text file in output.

The most abundant unique sequence of each OTU cluster (family or, when possible, species) was selected as representative, then aligned by SINA [49], mounted in ARB [50] and subjected to chimera check (before submission in GenBank) by Pintail v. 1.1 software [51]. Rarefaction curves 
were generated from families of clustered OTUs using EcoSim v.1.2d [52], separately for each percentage of similarity.

The 97\% similarity clustered consensus sequences were deposited in Genbank under accession numbers KC896717-KC896758; raw reads were deposited in NCBI Sequence Read Archive with accession number SRR837401 (reference: BioProject PRJNA196888).

\section{Bacterial isolation and identification}

The aerobic cultivable bacterial fraction was analysed on three lots of larvae sampled in April 2011 in Palermo (lots A, B, C). Each pool consisted of three larval guts and their total average weight was $3.68 \mathrm{~g}$ (SD: 0.18).

RPW guts were aseptically extracted from each larva, then the content of three guts was pooled, serially diluted in sterile physiological solution, and plated on NA. The plates were incubated for $72 \mathrm{~h}$ at $28^{\circ} \mathrm{C}$. At the end of the incubation period, colonies were counted and single colonies were streaked to purity on the same fresh medium. The isolates were grouped into OTUs by ARDRA analysis. The whole $16 \mathrm{~S}$ gene was amplified by colony PCR using the bacterial universal primers fD1 and rD1 [53], as described elsewhere [2], and the amplicons were digested using the restriction enzymes AluI and AfaI. Representative isolates of each OTU were randomly chosen for bidirectional sequencing of the $16 \mathrm{~S}$ rRNA gene. Colonies growing on sterilization control plates were streaked to purity and analysed by ARDRA and 16SrRNA gene partial sequencing. In the same time enrichment cultures in a sorbitol-containing medium at pH 3.5 were set as described by Yamada et al. [42], for the isolation of acetic acid bacteria (AAB). When microbial growth occurred, the microorganisms were streaked on $\mathrm{CaCO}_{3}$ agar plates and colonies capable of causing clearing of the $\mathrm{CaCO}_{3}$ were selected and identified by partial sequencing of PCR-amplified 16SrRNA gene. Sequences were subjected to NCBI nucleotide BLAST search as described above. Amplified sequences and close relatives were aligned using SILVA alignment tool [54]. Alignment was merged with SSUref_108_Silva_NR database and manually checked with ARB [50]. After alignment, the neighbour-joining algorithm of ARB package was used to generate the phylogenetic trees based on distance analysis for $16 \mathrm{~S}$ rRNA genes. The robustness of inferred topologies was tested by bootstrap re-sampling using the same distance model (1000 replicates). 16S rRNA gene sequences were deposited in Genbank under accessions number KC584753 to KC584772 (gut isolates), KC763479-80 (cuticle isolates) and $\mathrm{KC} 763478$ (AAB enrichment culture isolate).

\section{Addendum}

Recently, just before this manuscript was submitted to this journal, a study on the seasonal variation of the intestinal metagenomes of $R$. ferrugineus larvae and adults from date palms was published [55]. This study reports that, at the phylum level, Proteobacteria dominate the gut metagenomes of date palm larvae, followed by Tenericutes or Firmicutes depending on the season. The authors identify Klebsiella pneumoniae and Lactococcus lactis as the dominant species of the microbiota. Bacteroidetes are found at negligible levels and the genus Dysgonomonas is not detected. Differences between larvae from date palm and those from Canary palm may be attributed to the host plant species.

The metagenomic analysis carried out by Jia et al. [55] describes a few ORFs involved in the hydrolisis of cellulolose and high abundance of ORFs related to utilization of disaccharides and simple sugars that are abundantly available in the palm sap [24]. Sap sugars are presumably the main $C$ and energy source for the RPW larvae and its microbiota, that is dominated by fermenting bacteria to obtain several metabolites including lactate and acetate.

\section{Additional files}

\begin{tabular}{|c|}
\hline $\begin{array}{l}\text { Additional file 1: Phoenix canariensis infested by Rhynchophorous } \\
\text { ferrugineus (A and B); different infested palms cut in the higher part } \\
\text { are shown. Larvae of the red palm weevil (RPW) Rhynchophorus } \\
\text { ferrugineus, found inside the body of the infested palm (C). Female adult } \\
\text { specimen of Rhynchophorus ferrugineus Olivier (Coleoptera, Curculionidae, } \\
\text { Rhynchophorinae) (D). }\end{array}$ \\
\hline $\begin{array}{l}\text { Additional file 2: Complete results of } 16 \text { S pyrotag sequence } \\
\text { clustering and taxonomic assignment by RDP of clusters and } \\
\text { singletons at } 90 \%, 95 \% \text { and } 97 \% \text { ID. }\end{array}$ \\
\hline $\begin{array}{l}\text { Additional file 3: Relative abundance of bacterial families in the } \\
\text { gut of RPW larvae as detected by pyrosequencing of the 16SrRNA } \\
\text { gene V2 region. }\end{array}$ \\
\hline $\begin{array}{l}\text { Additional file 4: Phylogenetic tree of } 16 \text { S rRNA gene amplicons } \\
\text { clustered at } 97 \% \text { consensus. The tree was constructed by neighbour-joining } \\
\text { method and Jukes Cantor distance matrix using the arb software. Bootstraps } \\
\text { were calculated over } 1000 \text { random repetitions: values }>60 \text { and }<=75 \text { are } \\
\text { shown as open circles, whereas values }>75 \text { are shown as filled circles. } \\
\text { Sequences obtained in this study are indicated in bold. The scale bar } \\
\text { represents 10\% sequence divergence. }\end{array}$ \\
\hline $\begin{array}{l}\text { Additional file 5: Phylogenetic tree of } 16 \mathrm{~S} \text { rDNA sequences of RPW } \\
\text { gut isolates and related sequences, as determined by distance } \\
\text { Jukes-Cantor analysis. One thousand boostrap analyses were } \\
\text { conducted and values greater than } 60 \% \text { are reported. Two Archaea } \\
\text { sequences of Methanopirus kandleri and Korarchaeum cryptophilum were } \\
\text { used as outgroup. The scale bar represents the expected number of } \\
\text { changes per nucleotide position. Colors indicate the isolation site or the } \\
\text { isolation procedure described in this work and in [2]. Blue: RPW gut } \\
\text { isolates on NA; Red: frass bacteria; Green: palm bacterial endophytes; } \\
\text { Fuchsia: gut isolates obtained from enrichment cultures on CMC; Yellow: } \\
\text { larval cuticle bacteria isolated from sterilization control plates. } \\
\text { Isolate_RPWenrichAAB* was isolated from the RPW larval gut from } \\
\text { enrichment cultures set for for Acetic Acid Bacteria isolation [42]. }\end{array}$ \\
\hline $\begin{array}{l}\text { Additional file } 6 \text { : Identities of } 16 \text { S rRNA gene sequences of } \\
\text { cellulolytic bacterial strains isolated from the RPW gut by } \\
\text { enrichment cultures [2] with the RDP } 454 \text { consensus sequences } \\
\text { clustered at } 97 \% \text { ID of the RPW microbiota. Only identities above } 90 \% \\
\text { are shown. }\end{array}$ \\
\hline
\end{tabular}

Competing interests

The authors declare that they have no competing interests. 


\section{Authors' contributions}

MT projected and carried out the microbiological and molecular analyses, EM performed the bioinformatic analyses, BM identified and collected the insects in the field and manipulated them for the gut microbiota analyses, SC constructed the phylogeny trees and helped to draft the manuscript, $\mathrm{PQ}$ conceived and coordinated the study and drafted the manuscript. All authors read and approved the final manuscript.

\section{Acknowledgements}

The authors thank Maria Grazia Cusimano, Rosella Maggio and Flavia Contino for technical assistance in bacterial isolation, DNA extraction and amplification, and control of DNA quality for pyrosequencing, respectively. This work was partially financed by a grant from the Italian Ministry of Education (PRIN Program 2008 prot. 200847CA28-002) and by the University of Palermo (project FFR 2012 ATE-0322 N.2785).

\section{Author details}

'Department STEBICEF, University of Palermo Viale delle Scienze Ed.16, Palermo 90128, Italy. ${ }^{2}$ Istituto per I'Ambiente Marino Costiero (C.N.R. - IAMC) U.O.S. di Messina, Spianata S. Raineri, 86, Messina 98122, Italy. ${ }^{3}$ Istituto per I'Ambiente Marino Costiero (C.N.R. - IAMC) U.O.S. di Capo Granitola, Via del Mare, 3 Torretta-Granitola, Mazara, TP 91021, Italy.

Received: 9 December 2013 Accepted: 25 April 2014

Published: 30 May 2014

\section{References}

1. Cox ML: Red palm weevil, Rhynchophorus ferrugineus in Egypt. FAO Pl Prot Bul 1993, 41:30-31.

2. Butera G, Ferraro C, Colazza S, Alonzo G, Quatrini P: The culturable bacterial community of frass produced by larvae of Rhynchophorus ferrugineus Olivier (Coleoptera: Curculionidae) in the Canary island date palm. Lett Appl Microbiol 2012, 54:530-536.

3. Dembilio Ó, Jacas JA: Basic bio-ecological parameters of the invasive Red Palm Weevil, Rhynchophorus ferrugineus (Coleoptera: Curculionidae), in Phoenix canariensis under Mediterranean climate. Bull Entomol Res 2011, 101:153-163.

4. Faleiro JR: A review on the issues and management of red palm weevil Rhynchophorus ferrugineus (Coleoptera: Rhynchophoridae) in coconut and date palm during the last one hundred years. Internat I Trop Insect Sci 2006, 26:135-154

5. Ferry M, Gomez S: The Red Palm Weevil in the Mediterranean area. Palms 2002, 46:172-178.

6. Engel P, Moran NA: The gut microbiota of insects - diversity in structure and function. FEMS Microbiol Rev 2013, 37:699-735.

7. Hongoh Y: Diversity and genomes of uncultured microbial symbionts in the termite gut. Biosci Biotechnol Biochem 2010, 74:1145-1151.

8. Colman DR, Toolson EC, Takacs-Vesbach CD: Do diet and taxonomy influence insect gut bacterial communities? Mol Ecol 2012, 21:5124-5137.

9. Rosenberg E, Zilber-Rosenberg I: Symbiosis and development: the hologenome concept. Birth Defects Res (Part C) 2011, 93:56-66.

10. Dillon RJ, Dillon VM: The gut bacteria of insects: non-pathogenic interactions. Annu Rev Entomol 2004, 49:71-92.

11. Kaufman MG, Klug MJ: The contribution of hindgut bacteria to dietary carbohydrate utilization by crickets (Orthoptera, Gryllidae). Comp Biochem Physiol A Physiol 1991, 98:117-123.

12. Chakravorty S, Helb D, Burday M, Connell N, Alland D: A detailed analysis of 165 ribosomal RNA gene segments for the diagnosis of pathogenic bacteria. J Microbiol Methods 2007, 69:330-339.

13. Tang X, Freitak D, Vogel H, Ping L, Shao Y, Cordero EA, Andersen G, Westermann M, Heckel DG, Boland W: Complexity and variability of gut commensal microbiota in polyphagous lepidopteran larvae. PLoS One 2012, 7(7):e36978. doi:10.1371/journal.pone.0036978.

14. Shivaji S, Chaturvedi P, Suresh K, Reddy GS, Dutt CB, Wainwright M, Narlikar JV, Bhargava PM: Bacillus aerius sp. nov., Bacillus aerophilus sp. nov., Bacillus stratosphericus sp. nov. and Bacillus altitudinis sp. nov., isolated from cryogenic tubes used for collecting air samples from high altitudes. Int J Syst Evol Microbiol 2006, 56:1465-1473.

15. Suzuki T, Yamasato K: Phylogeny of spore-forming lactic acid bacteria based on 16S rRNA gene sequences. FEMS Microbiol Lett 1994, 115:13-17.
16. Crotti E, Rizzi A, Chouaia B, Ricci I, Favia G, Alma A, Sacchi L, Bourtzis K, Mandrioli M, Cherif A, Bandi C, Daffonchio D: Acetic acid bacteria, newly emerging symbionts of insects. Appl Environ Microbiol 2010, 76:6963-6970.

17. Claesson MJ, Wang QO, O'Sullivan O, Greene-Diniz R, Cole JR, Ross RP, OToole PW: Comparison of two next-generation sequencing technologies for resolving highly complex microbiota composition using tandem variable 165 rRNA gene regions. Nucleic Acids Res 2010, 38(22):e200. doi:10.1093/nar/gkq873.

18. Milani C, Hevia A, Foroni E, Duranti S, Turroni F, Lugli A, Sanchez B, Martin R, Gueimonde M, van Sinderen D, Margolles A, Ventura M: Assessing the fecal microbiota: an optimized ion torrent $16 \mathrm{~S}$ rRNA gene-based analysis protocol. PLoS One 2013, 8(7):e68739. doi:10.1371/journal.pone.0068739.

19. Youssef N, Sheik CS, Krumholz LR, Najar FZ, Roe BA, Elshahed MS: Comparison of species richness estimates obtained using nearly complete fragments and simulated pyrosequencing-generated fragments in 16S rRNA gene-based environmental surveys. Appl Environ Microbiol 2009, 75:5227-5236.

20. Morales-Jiménez J, Zuniga G, Villa-Tanaca L, Hernandez-Rodriguez C: Bacterial community and nitrogen fixation in the red turpentine beetle, Dendroctonus valens LeConte (Coleoptera: Curculionidae: Scolytinae). Microb Ecol 2009, 58:879-891.

21. Chandler JA, Morgan Lang J, Bhatnagar S, Eisen JA, Kopp: A bacterial communities of diverse drosophila species: ecological context of a hostmicrobe model system. PLoS Genet 2011, 7(9):e1002272. doi:10.1371/ journal.pgen.1002272.

22. Nagnan P, Cain AH, Rochat D: Extraction et identification des composés volatils de la sève de palmier à huile fermentée (vin de palme) attractifs potentiels pour le charancon du palmier. Oléagineux 1992, 47:135-142.

23. Behar A, Yuval B, Jurkevitch E: Enterobacteria-mediated nitrogen fixation in natural populations of the fruit fly Ceratitis capitata. Mol Ecol 2005, 14:2637-2643

24. Chandrasekhar K, Sreevani S, Seshapani P, Pramodhakumari J: A Review on palm wine. J Res Biol Sci 2012, 2(1):33-38.

25. Santo Domingo JW, Kaufman MG, Klug MJ, Tiedje JM: Characterization of the cricket hindgut microbiota with fluorescently labeled rRNA-targeted oligonucleotide probes. Appl Environ Microbiol 1998, 64:752-755.

26. Wong CN, Ng P, Douglas AE: Low-diversity bacterial community in the gut of the fruitfly Drosophila melanogaster. Environ Microbiol 2011, 13:1889-1900

27. Mazza G, Arizza V, Baracchi D, Barzanti GP, Benvenuti C, Francardi V, Frandi A, Gherardi F, Longo S, Manachini B, Perito B, Rumine P, Schillaci D, Turillazzi $S$, Cervo R: Antimicrobial activity of the red palm weevil Rhynchophorus ferrugineus. Bull Insectol 2011, 64:33-41.

28. Rinke R, Costa AS, Fonseca FP, Almeida LC, Delalibera Júnior I, HenriqueSilva F: Microbial diversity in the larval gut of field and laboratory populations of the sugarcane weevil Sphenophorus levis (Coleoptera, Curculionidae). Genet Mol Res 2011, 10:2679-2691.

29. Hofstad T, Olsen I, Eribe ER, Falsen E, Collins MD, Lawson PA: Dysgonomonas gen. nov. to accommodate Dysgonomonas gadei sp. nov., an organism isolated from a human gall bladder, and Dysgonomonas capnocytophagoides (formerly CDC group DF-3). Int J Syst Evol Microbiol 2000, 50:2189-2195.

30. Watanabe K, Miyahara M, Shimoyama T, Hashimoto K: Population dynamics and current-generation mechanisms in cassette-electrode microbial fuel cells. Appl Microbiol Biotechnol 2011, 92:1307-1314.

31. Gupta AK, Nayduch D, Verma P, Shah B, Ghate HV, Patole MS, Shouche YS: Phylogenetic characterization of bacteria in the gut of house flies (Musca domestica L.). FEMS Microbiol Ecol 2012, 79:581-593.

32. Campbell BC, Bragg TS, Turner CE: Phylogeny of symbiotic bacteria of four weevil species (Coleoptera:Curculionidae) based on analysis of $16 \mathrm{~S}$ ribosomal DNA. Insect Biochem Molec Biol 1992, 22:415-421.

33. Tully JG, Whitcomb RF, Hackett KJ, Williamson DL, Laigret F, Carle P, Bové $\mathrm{JM}$, Henegar RB, Ellis NM, Dodge DE, Adams J: Entomoplasma freundtii sp. nov., a new species from a green tiger beetle (Coleoptera: Cicindelidae). Int J Syst Bacteriol 1998, 48:1197-1204.

34. Yu H, Wang Z, Liu L, Xia Y, Cao Y, Yin Y: Analysis of the intestinal microflora in Hepialus gonggaensis larvae using $16 \mathrm{~S}$ rRNA sequences. Curr Microbiol 2008, 56:391-396.

35. Suen G, Scott JJ, Aylward FO, Adams SM, Tringe SG, Pinto-Tomás AA, Foster CE, Pauly M, Weimer PJ, Barry KW, Goodwin LA, Bouffard P, Li L, Osterberger J, Harkins TT, Slater SC, Donohue TJ, Currie CR: An insect herbivore 
microbiome with high plant biomass-degrading capacity. PLoS Genet 2010, 6(9):e1001129. doi:10.1371/journal.pgen.1001129.

36. Paoletti MG, Mazzon L, Martinez-Sañudo I, Simonato M, Beggio M, Dreon AL, Pamio A, Brilli M, Dorigo L, Engel AS, Tondello A, Baldan B, Concheri G, Squartini A: A unique midgut-associated bacterial community hosted by the cave beetle Cansiliella servadeii (Coleoptera: Leptodirini) reveals parallel phylogenetic divergences from universal gut-specific ancestors. BMC Microbiol 2013, 13:129.

37. Guarino S, Lo Bue P, Peri E, Colazza S: Responses of Rhynchophorus ferrugineus adults to selected synthetic palm esters: electroantennographic studies and trap catches in an urban environment. Pest Manag Sci 2011, 67:77-81.

38. Broderick NA, Goodman RM, Handelsman J, Raffa KF: Effect of host diet and insect source on synergy of gypsy moth (Lepidoptera: Lymantriidae) mortality to Bacillus thuringiensis subsp. kurstaki by zwittermicin A. Environ Entomol 2003, 32:387-391.

39. Abe F, Ohkusu M, Kawamoto S, Sone K, Hata K: Isolation of yeasts from palm tissues damaged by the red palm weevil and their possible effect on the weevil overwintering. Mycoscience 2010, 51:215-223.

40. Hassan AA, Akineden O, Kress C, Estuningsih S, Schneider E, Usleber E: Characterization of the gene encoding the 16S rRNA of Enterobacter sakazakii and development of a species-specific PCR method. Int J Food Microbiol 2007, 116:214-220.

41. Toledo AV, Alippi AM, de Remes Lenicov AM: Growth inhibition of Beauveria bassiana by bacteria isolated from the cuticular surface of the corn leafhopper, Dalbulus maidis and the planthopper, Delphacodes kuscheli, two important vectors of maize pathogens. J Insect Sci 2011, 11:1-13.

42. Yamada Y, Katsura K, Kawasaki H, Widyastuti Y, Saono S, Seki T, Uchimura T, Komagata K: Asaia bogorensis gen. nov., sp. nov., an unusual acetic acid bacterium in the alpha-Proteobacteria. Int I Syst Evol Microbiol 2000, 50:823-829.

43. Doolittle M, Raina A, Lax A, Boopathy R: Presence of nitrogen fixing Klebsiella pneumoniae in the gut of the Formosan subterranean termite (Coptotermes formosanus). Bioresour Technol 2008, 99:3297-3300.

44. Pittman GW, Brumbley SM, Allsopp PG, O'Neill SL: "Endomicrobia" and other bacteria associated with the hindgut of Dermolepida albohirtum larvae. Appl Environ Microbiol 2008, 74:762-767.

45. Muyzer G, DeWaal EC, Uitterlinden AG: Profiling of complex microbial populations by denaturing gradient gel electrophoresis analysis of polymerase chain reaction-amplified genes coding for 16S rRNA. Appl Environ Microbiol 1993, 59:695-700.

46. Hamady M, Walker JJ, Harris JH, Gold NJ, Knight R: Error-correcting barcoded primers allow hundreds of samples to be pyrosequenced in multiplex. Nat Methods 2008, 5:235-237.

47. Niu B, Fu L, Sun S, Li W: Artificial and natural duplicates in pyrosequencing reads of metagenomic data. BMC Bioinforma 2010, 13:11-187.

48. Cole JR, Wang Q, Fish JA, Chai B, McGarrell DM, Sun Y, Brown CT, PorrasAlfaro A, Kuske CR, Tiedje JM: Ribosomal database project: data and tools for high throughput rRNA analysis. Nucl Acids Res 2014, 41(Database issue):D633-D642. doi:10.1093/nar/gkt1244.

49. Pruesse E, Peplies J, Glöckner FO: SINA: accurate high-throughput multiple sequence alignment of ribosomal RNA genes. Bioinformatics 2012, 28:1823-1829.

50. Ludwig W, Strunk O, Westram R, Richter L, Meier H, Yadhukumar, Buchner A, Lai T, Steppi S, Jobb G, Förster W, Brettske I, Gerber S, Ginhart AW, Gross O, Grumann S, Hermann S, Jost R, König A, Liss T, Lüssmann R, May M, Nonhoff B, Reichel B, Strehlow R, Stamatakis A, Stuckmann N, Vilbig A, Lenke M, Ludwig T, Bode A, Schleifer KH: ARB: a software environment for sequence data. Nucleic Acids Res 2004, 32:1363-1371.

51. Ashelford KE, Chuzhanova NA, Fry JC, Jones AJ, Weightman AJ: At least 1 in 20165 rRNA sequence records currently held in public repositories is estimated to contain substantial anomalies. Appl Environ Microbiol 2005, 71:7724-7736

52. Entsminger GL: EcoSim Professional: Null Modelling Software for Ecologists, Version 1. Acquired Intelligence Inc., Kesey-Bear, \& Pinyon Publishing; 2012. http://garyentsminger.com/ecosim/index.htm.

53. Weisburg WG, Barns SM, Pelletier DA, Lane DJ: 16S Ribosomal DNA amplification for phylogenetic study. J Bacteriol 1991, 173:697-703.
54. Pruesse E, Quast C, Knittel K, Fuchs BM, Ludwig W, Peplies J, Glöckner FO: SILVA: a comprehensive online resource for quality checked and aligned ribosomal RNA sequence data compatible with ARB. Nucleic Acids Res 2007, 35:7188-7196.

55. Jia S, Zhang X, Zhang G, Yin A, Zhang S, Li F, Wang L, Zhao D, Yun Q, Tala, Wang J, Sun G, Baabdullah M, Yu X, Hu S, Al-Mssallem IS, Yu J: Seasonally variable intestinal metagenomes of the red palm weevil (Rhynchophorus ferrugineus). Environ Microbiol 2013, 15:3020-3029.

doi:10.1186/1471-2180-14-136

Cite this article as: Tagliavia et al:: The gut microbiota of larvae of Rhynchophorus ferrugineus Oliver (Coleoptera: Curculionidae). BMC Microbiology 2014 14:136.

\section{Submit your next manuscript to BioMed Central and take full advantage of:}

- Convenient online submission

- Thorough peer review

- No space constraints or color figure charges

- Immediate publication on acceptance

- Inclusion in PubMed, CAS, Scopus and Google Scholar

- Research which is freely available for redistribution

Submit your manuscript at www.biomedcentral.com/submit
C BioMed Central 